\section{Yellow rain and}

\section{the bee}

SIR - Criticism of the bee faeces theory by Rosen et al. ${ }^{1}$ is misleading and inaccurate. Their assignment of the burden of proof to US government sceptics is misplaced.

The authors assert that "heavy" invasion of substrate is a prerequisite for high toxin levels and that they never observed any "fluffy" mycelium in their samples. In fact, the relationship between mycelial mass and toxin production by Fusarium spp. is extremely variable, ranging well over three orders of magnitude. Further, the authors neglect to mention that they did not microscopically examine their samples. While at the University of Wisconsin, I examined bee faeces samples from Thailand. No mycelial growth was obvious but Fusarium spp. were present at counts as high as 1,000 colony forming units per milligram. At least one of these strains is capable of producing greater than 1,000 p.p.m. zearalenone under laboratory conditions. It is curious that the authors choose to subject their samples to highly sophisticated GC-MS analysis without also determining the mycoflora present by dilution plating and/or microscopy.

Rosen et al. claim that Type A and Type B trichothecenes are "never (except in one case)" found together. This "lone exception" is purported to be a corn sample collected in France. As at least one of the authors should know, this is incorrect ${ }^{2}$.

In their final paragraph, Rosen et al. state "We are amazed that the proponents of this theory have not yet presented one iota of evidence that trichothecenes can be produced naturally ...". When one considers the resources available to the US government's laboratories and their intense efforts to identify additional positive samples, it is truly "amazing" that none have been found. More importantly, it is astonishing that the authors imply that the burden of proof should lay with the sceptics. Meselson and others have merely advanced an alternative explanation that is consistent with all physical evidence. In contrast, the US State Department has termed its evidence as "unequivocal" and the so-called "smoking gun".

This "conclusive" evidence has been the basis of serious allegations of Soviet treaty violations and has directly affected such issues as the binary weapons programme and disarmament negotiations. Under those circumstances, who has the burden of proof?

180 Kimball Way,

South San Francisco,

California 94080, USA

I. Rosen, J.D., Cohen, H., Mirocha, C.J. \& Schiefer, H.B Nature 313, 271 (1985)

2. Mirocha, C.J., Schauerhamer, B., Christensen, C.M \& Koddedahl, T. Appl. Envir. Microbiol. 38, 557.558, (1979)

\section{Fivefold symmetry in boron and borides}

SIR - A recent News and Views article presented an interesting discussion of fivefold crystal symmetries ${ }^{1}$, in particular relating to the recent experiments on $\mathrm{Mn}-\mathrm{Al}$ alloys $^{2}$. I would like to draw attention to the fact that the fivefold symmetry is also a characteristic feature of the crystalline boron (beta-rhombohedral modification) as well as some borides (such as $\mathrm{AIB}_{12}$ ). The crystal lattice of $\beta$-boron is formed by the repetitive pattern of icosahedrons with the unit cell having 105 non-equivalent atoms. This is by itself rather peculiar for an elemental material. This fact, strikingly little known outside the boron specialists, leads to a number of non-trivial consequences. One example is the possibility of hopping conductivity in an intrinsic (and not doped) semiconductor ${ }^{3}$. Therefore, the naturally occurring fivefold symmetry has another area of manifestation, besides the $\mathrm{Mn}-\mathrm{Al}$ alloys mentioned.

A.A. BEREZIN

Department of Engineering Physics, McMaster University, Hamilton, Ontario, Canada L8S 4MI

1. Maddox, J. Nature 313, 263 (1985).

2. Shechtman, D. et al. 53, 1951 (1984)

3. Berezin, A.A. J. chem. Phys. 80, 1241 (1984).

\section{King Midas and the Red Queen}

SIR - Benton's commentary ${ }^{1}$ on recent tests of the Red Queen hypothesis draws attention to the difficulty of distinguishing changes in the biotic environment from those in the abiotic one, over geological time. The hypothesis demands that evolution is driven by an antagonistic biota. However, mutualistic interactions among species cause the biotic environment to improve rather than to deteriorate $^{2}$, and the need for continual change just 'to keep in the same place' is lost. Thus, an alternative way of testing the hypothesis is to compare the rates of evolution of taxa in antagonistic environments with those found in mutualistic ones, specifically in associations where one species lives inside the cells of another. We suggest that the homeostatic intracellular environment experienced by mutualistic endosymbionts is buffered from antagonists while, at the same time, subject to much the same major abiotic changes (such as climatic perturbations) as the environment of their hosts.

Nature has been kind enough to provide many such evolutionary experiments, including mutualistic symbioses as diverse as algae within coelenterates (for example, corals), and bacteria within plants (for example leguminous and non-leguminous nodules, see Table 1 of ref. 2). A striking feature of these and other mutualistic associations is that the symbionts which live intracellularly for a prolonged period are represented by a much smaller number of taxa than their external partners ${ }^{2}$. We argue that this supports the view that biotic interactions do play an important part in evolutionary processes ${ }^{2,3}$.

For those inclined to regal metaphors, we would contrast the Red Queen of deteriorating, antagonistic environments, with King Midas's golden touch of species in improving, mutualistic environments, although the outcome is evidently more stable for mutualistic species than it was for the king himself ${ }^{3}$.

Department of Biology,

R. LAW

University of York,

York YOI SDD, UK

Department of Botany,

D.H. LEWIS

University of Sheffield,

Sheffield S1O 2TN, UK

1. Benton, M.J. Nature 313, 734 (1985)

2. Law, R. \& Lewis, D.H. Biol. J. Linn Soc. 20, 249 (1983)

3. Law, R. in The Biology of Mutualism: Ecology and Evolution (ed. Boucher, D.H.) (Croom-Helm, London, in the press).

\section{Biological role of IgG hinge region}

SIR - We feel compelled to point out that an article correlating IgG antibody flexibility and complement fixation by the classical pathway 1 , while an important piece of work, is a regrettable example of authors failing to acknowledge the intellectual and experimental contributions of earlier workers. Surely the findings of Oi $e t$ al. must be considered a quantitative refinement of principles laid out originally by us in a series of papers over the past decade (for example refs 2-6). The following ", for example, is unambiguous:

(These) studies ... highlight the crucial role played by the hinge region and its constituent disulfides in allowing $\mathrm{IgG}$ to perform its biological effector functions.

An essential feature of this role is to limit segmental flexibility; yet this flexibility seems to be important for optimal antigen binding. Thus, the hinge serves to balance the antigen-dependent and antigen-independent flexibility requirements of the molecule.

It is surprising that the editorial review practices of Nature can be so accommodating to what we believe an imbalanced presentation.

K.J. DORRINGTON D.E. ISENMAN

M.H. KLEIN

R.H. PAINTER

D.G. ROMANS

Department of Biochemistry,

University of Toronto,

Toronto, Canada MSS 1 A8

I. Oi, V.T. et al. Nature 307, 136-140 (1984)

2. Isenman, D.E., Dorrington, K.J. \& Painter, R.H. J. Immun. 114, 1726-1729 (1975).

3. Romans, D.G. Tilley, C.A., Crookston, M.C., Falk, R.E. \& Dorrington, K.J. Proc, natn. Acad. Sci. 74, 2531-2535 (1977)

4. Romans, D.G., Tilley, C.A. \& Dorrington, K.J. Molec. Im mun. 16, 859-879 (1979)

5. Klein, M. et al. Proc, natn. Acad. Sci. U.S. A. 78, \$24-\$28 (1981)

6. Dorrington, K.J. \& Klein, M.H. Molec. Immun. 19, 1215 $1221(1982)$ 